\title{
Thermal Radiofrequency in Lung Cancer Pain
}

\author{
AHMED F. AHMED, M.Sc.; RAAFAT R. MAHFOUZ, M.D.; EMAD G. SALEH, M.D.; \\ SOMAYA A. EL SHEIKH, M.D. and MOHGA A. SAMY, M.D.
}

The Department of Anesthesia and Pain Relief, National Cancer Institute, Cairo University

\begin{abstract}
Background: Lung cancer is one of most common malignancies worldwide. Pain is one of the most prevalent symptoms in patients diagnosed with lung cancer. Many therapeutic modalities proposed to provide pain relief in those patients. The aim of this study was to assess of the safety and effectiveness of Thermal Radio Frequency (TRF) of Dorsal root ganglion in treatment of chronic malignant thoracic pain.
\end{abstract}

Aim of Study: Was to assess of the safety and effectiveness of Thermal Radio Frequency (TRF) of Dorsal root ganglion in treatment of chronic malignant thoracic pain.

Patients and Methods: This prospective interventional study included 30 patients with lung cancer pain. The patients received TRF of Dorsal root ganglion corresponding to related pain dermatome at national cancer institute during the period from 1 st of January 2015 to end of December 2018.

Results: Visual analog scale, quality-of-life and quality of sleep scores were improved significant at Day 1, 1 week, $1 \mathrm{~m}$ and $3 \mathrm{~m}$ as compared to pre block. On assessment of postoperative complication four cases had dorsal back pain and two cases had neuritis.

Conclusions: TRF leads to pain relief on long term but with minimal concerns in safety profile.

Key Words: Thermal radiofrequency - Lung cancer-Chronic pain.

\section{Introduction}

LUNG cancer is the most common cancer in the world with 1.61 million new case diagnosed every year [1]. Pain is the most common symptom in cancer patients in general and in lung cancer specifically. The majority of patients with lung cancer have an advanced stage of the disease at clinical presentation. Symptoms may result from local effects of tumor, from regional or distant spread, or from distant effects not related to metastases (paraneoplastic syndromes) [2].

Patients with lung cancer experience more distressing symptoms than patients with other types

Correspondence to: Dr. Ahmed F. Ahmed, E-Mail: drfahmof@gmail.com of cancers [3]. Symptoms such as pain may be associated with worsening of other symptoms including respiratory distress, depression and fatigue [4] and may affect quality of life [5]

Pain resulting from lung cancer can be classified by two methods: either by the type of pain or according to the origin of the pain. The location or origin of the pain may determine the type of pain experienced. Pain can also be affected by the histological type and biological behavior of the lung cancer present. Pain in patients with lung cancer can be differentiated according to its origin, namely intra-thoracic or extra thoracic, the latter of which may be the consequence of cancer complications [6].

In the management of chronic cancer pain, the ability to ablate or modulate sensory nerve fibers to cause analgesia has intrigued physicians for many years. Chronic cancer pain is commonly controlled with pharmacologic agents alone. Even multimodal therapy-combining physical or occupational therapy, psychological interventions, and interventional procedures-may be suboptimal in providing adequate analgesia [7].

TRF uses a constant high-frequency electric current $(500,000 \mathrm{~Hz})$ to produce tissue temperatures of $45^{\circ} \mathrm{C}$ or more, resulting in neuroablative thermo coagulation. Thus, TRF is a neuroablative technique that uses heat for controlled destruction of nociceptive pathways [8]. In TRF, heating during RF causes many cells to die rapidly if tissue temperatures reach above $45^{\circ} \mathrm{C}$. Neuroablation is produced whether the electrode is placed inside the dorsal root ganglion (DRG) or onto a peripheral nerve [9].

The aim of this study was to assess of the safety and effectiveness of TRF of Dorsal root ganglion in treatment of chronic malignant thoracic pain. 


\section{Patients and Methods}

This prospective interventional study included 30 patients with lung cancer pain selected from pain clinic at National Cancer Institute after approval from Ethical Committee and obtaining informed written consent at national cancer institute during the period from ${ }^{1 \text { st }}$ of January 2015 to end of December 2018.

The patients were received TRF of the thoracic dorsal root ganglion of related pain dermatome.

The Inclusion criteria were patients with chest pain (anterior, posterior) due to lung cancer, failed medical treatment, ppresence of complication e.g: vomiting, constipation, narcosis of opioids, age between (18y-65y), good general condition and ability to lie prone, and ability to lie lateral on the painful side for at least 1 hour.

The exclusion criteria were Patients with coagulation defects neurological defect, epidural metastases, vertebral collapse, osteolytic lesions at entry site of the needle, Local infection, Psychiatric illnesses, sepsis, Poor general condition and severe respiratory distress.

Patients were subjected to aassessment before procedure: Complete personal history, psychological examination, physical examination, pain assessment (VAS, sleep rhythm, physical activity) laboratory: CBC. Coagulation profile (PC\%- PTINR). Radiological: Plain chest X-ray and MRI spine.

\section{Thermal radiofrequency ablation of DRG tech- nique:}

The patient was placed prone on a small pillow located under the chest, and the back of the patient was sterilized using $8 \%$ povidone iodide and draped. The needle was a Baylis RF needle (100 $\mathrm{mm}$ length, $10 \mathrm{~mm}$ active tip, curved, G20, sharp needle) (Baylis Medical Company Inc. Montreal, QC Canada). The selected level was checked by history, local examination for rib tenderness and possible neuropathic characters, e.g., allodynia. The fluoroscopic postero/anterior (PA) view was taken and squaring (alignment) of the targeted vertebra was attained by cephalocaudal orientation of the C-arm. An ipsilateral oblique view of $15^{\circ}$ was completed and then the port of needle entry was located at the lower $1 / 3$ to $1 / 4$ of the lateral vertebral edge, under the articular pillar and the halo of the transverse process. As a rule, the port of needle entry must be within $4 \mathrm{~cm}$ of the midline (Rule of 4) to avoid injuring the parietal pleura.
Lidocaine $1 \%$ (Debocaine 2\%, Sigma-Tec, Egypt) was used for local infiltration of the skin and subcutaneous tissues. The RF cannula was advanced using the trajectory (tunnel) technique with a $15^{\circ}$ oblique view and then with a deadlateral view until the needle tip stopped at the lower- or mid-foraminal zone and behind the central line to avoid segmental blood supply and nerve root injury. After a negative aspiration for blood, air or CSF, $0.5-1.0 \mathrm{ml}$ of iohexol contrast medium (Omnipaque TM, Nycomed, Ireland) was injected to delineate the dorsal root ganglia, nerve roots, epidural space and the intercostal nerve path. A thermocouple electrode was inserted and sensory stimulation at $50 \mathrm{~Hz}$ and up to $0.5 \mathrm{v}$ and motor stimulation at $2 \mathrm{~Hz}$ and up to $1-1.5 \mathrm{v}$ was conducted to verify the needle tip position (tingling paresthesia and/or intercostal muscle contraction inside the needle).

Neural mapping of the affected dermatomal (intercostal) levels to be blocked was additionally performed by asking the patient if their original pain was at, above or below the level of sensory/ motor stimulation and if paresthesia is concordant with his original pain. Additionally, the impendence was checked (normal range is 150-250 $\Omega$ inside the neural foramen). The pain level was checked again after injecting a lidocainebetamethasone mixture ( $2 \mathrm{ml}$ of $2 \%$ lidocaine/ segment and $2 \mathrm{mg} / \mathrm{ml}$ betamethasone sodium phosphate plus $5 \mathrm{mg} / \mathrm{ml}$ betamethasone dipropionate) (Diprofos $2 \mathrm{mg}+5 \mathrm{mg} / \mathrm{ml}$, MSD/Schering-Plough, NJ, USA). After $2 \mathrm{~min}$, thermal lesioning was conducted using Baylis generator at $80^{\circ} \mathrm{C}$ for $120 \mathrm{~s}$ twice (up and medial then down and medial to enlarge the lesion size of the DRG), and both sensory and motor stimulation were repeated upon rotation of the needle tip.

The patient's back was dressed, and the patient was transferred to the recovery unit where vital signs and pain and neurological findings were checked for $1-2 \mathrm{~h}$ before dis- charge. The patient was instructed clearly to consult the pain team if adverse effects happened, namely, chest pain or dyspnea (pneumothorax) and neurological insults (motor deficits).

Pain assessment: The patient had been assessed: Pre procedure. Immediately after procedure, 1 week, 4 weeks, 12 weeks, for pain assessment using: Visual analogue scale VAS scale: Patients were asked to assess pain intensity using $100 \mathrm{~mm}$ visual analog scale (VAS). In which '0' represents no pain, "100" mean maximum pain imagined. Sleep rhythm (using sleep scale score): 0 normal rhythm, 1 
interrupted, 2 inefficient, 3 disturbed, 4 hard with hypnosis, 5 no sleep. Physical activity (using Physical activity scale score): 0 In work, 1 Sick leave, 2 Home activity, 3 Limited, 4 Isolated, 5 Bedridden. Consumption of analgesic drugs: Including opioids (Oxycontin ${ }^{\circledR}$ ), and adjuvants (Lyrica $\left.{ }^{\circledR}\right)$. Complications and side effects of RF: Deafferentation, neuritis, motor impairment, back pain, infection and sphincteric sequalae.

\section{Statistical analysis:}

Data were analyzed using SPPS version 16. Numerical data will be expressed as mean and standard deviation or median and rang as appropriate. Chi square test or Fisher's exact test will be used to examine the relation between qualitative variables. For quantitative data comparison between two groups were done using either parametric or nonparametric $t$-test as appropriate. A $p$-value of $\leq 0.05$ were considered significant.

\section{Results}

Mean age was $48.9( \pm 10.7), 30.0 \%$ were females and $70.0 \%$ were males. $16.7 \%$ had neuropathic burning pain, $20.0 \%$ had neuropathic lancinating pain, $3.3 \%$ had neuropathic lancinating burning pain, $13.3 \%$ had neuropathic lancinating tingling pain, $3.3 \%$ had neuropathic tingling pain, 3.3\% had neuropathic tingling electric pain, $40.0 \%$ had nociceptive dull ache pain, and $43.3 \%$ had pain on the left side and $56.7 \%$ had pain on the right side. $10.0 \%$ of pain was due adenocarcinoma, $13.3 \%$ of pain was due to bronchogenic origin, $63.3 \%$ was due mesothelioma, $3.3 \%$ was due post thoracotomy Adenocarcinoma and $10.0 \%$ was due small cell carcinoma. Mean number of affected dermatomes was $3.60( \pm 0.72)$. Table (1).

Mean pre block vas score was $7.67( \pm 1.09)$, mean Day 1 VAS score was $3.47( \pm 1.61)$, mean 1 week VAS score was $2.77( \pm 1.33)$ mean $1 \mathrm{~m}$ VAS score was $2.33( \pm 1.17)$ and mean $3 \mathrm{~m}$ VAS score was $2.57( \pm 1.17)$. There was significant improvement in Day 1, 1 week, $1 \mathrm{~m}$ and $3 \mathrm{~m}$ regarding to VAS score as compared to pre-block. Table (2).

Mean pre block Quality of life score was 4.20 $( \pm 0.66)$, mean Day 1 Quality of life score was 3.20 $( \pm 0.85)$, mean 1 week Quality of life score was $2.60( \pm 0.86)$, mean $1 \mathrm{~m}$ Quality of life score was $2.60( \pm 0.96)$ and mean $3 \mathrm{~m}$ Quality of life score was $2.50( \pm 1.25)$. There was significant improvement in Day 1, 1 week , $1 \mathrm{~m}$ and $3 \mathrm{~m}$ regarding to Quality of life as compared to pre-block. Table (3).
Mean pre block quality of sleep score was 3.47 $( \pm 0.94)$, mean Day 1 Quality of sleep score was $2.43( \pm 0.97)$, mean 1 week Quality of sleep score was $1.93( \pm 0.94)$, mean $1 \mathrm{~m}$ Quality of sleep score was $1.50( \pm 0.90)$ and mean $3 \mathrm{~m}$ Quality of sleep score was $2.03( \pm 1.22)$. There was significant improvement in Day 1,1 week, $1 \mathrm{~m}$ and $3 \mathrm{~m}$ regarding to Quality of sleep as compared to pre-block Table (4).

Table (1): Patients demographic data, type and site of pain and cause and number of affected dermatomes.

\begin{tabular}{|c|c|c|}
\hline \multicolumn{3}{|c|}{ Demographic data } \\
\hline \multicolumn{3}{|l|}{ Age: } \\
\hline Mean $\pm \mathrm{SD}$ & 48.9 & \pm 10.7 \\
\hline \multicolumn{3}{|l|}{ Sex: } \\
\hline Female & 9 & $30.0 \%$ \\
\hline Male & 21 & $70.0 \%$ \\
\hline \multicolumn{3}{|c|}{ Type and site of pain } \\
\hline \multicolumn{3}{|l|}{ Type of pain: } \\
\hline Neuropathic burning & 5 & $16.7 \%$ \\
\hline Neuropathic lancinating & 6 & $20.0 \%$ \\
\hline Neuropathic lancinating burning & 1 & $3.3 \%$ \\
\hline Neuropathic lancinating, tingling & 4 & $13.3 \%$ \\
\hline Neuropathic tingling & 1 & $3.3 \%$ \\
\hline Neuropathic tingling, electric & 1 & $3.3 \%$ \\
\hline Nociceptive dull ache & 12 & $40.0 \%$ \\
\hline \multicolumn{3}{|l|}{ Side of pain: } \\
\hline Left & 13 & $43.3 \%$ \\
\hline Right & 17 & $56.7 \%$ \\
\hline \multicolumn{3}{|c|}{ Cause and number of affected dermatomes } \\
\hline \multicolumn{3}{|l|}{ Cause of pain: } \\
\hline Adenocarcinoma & 3 & $10.0 \%$ \\
\hline Bronchogenic & 4 & $13.3 \%$ \\
\hline Mesothelioma & 19 & $63.3 \%$ \\
\hline Post thoracotomy Adenocarcinoma & 1 & $3.3 \%$ \\
\hline Post thoracotomy mesothelioma & 0 & $0.0 \%$ \\
\hline Small cell carcinoma & 3 & $10.0 \%$ \\
\hline \multicolumn{3}{|l|}{$\begin{array}{l}\text { Number of affected } \\
\text { dermatomes: }\end{array}$} \\
\hline Mean \pm SD & 3.60 & \pm 0.72 \\
\hline
\end{tabular}

Table (2): Comparison of the VAS score over time in patients.

\begin{tabular}{lcc}
\hline \multirow{2}{*}{ VAS } & TRF of thoracic dorsal root ganglion & \\
\cline { 2 - 3 } & Mean \pm SD & \\
\hline Pre-Block & $7.67 \pm 1.09$ & \\
Day 1 & $3.47 \pm 1.61$ & $<0.001$ \\
1 Week & $2.77 \pm 1.33$ & $<0.001$ \\
1 Month & $2.23 \pm 1.17$ & $<0.001$ \\
3 Months & $2.57 \pm 1.17$ & $<0.001$ \\
\hline
\end{tabular}


Table (3): Serial follow-up for quality-of-life Score in patients.

\begin{tabular}{lcc}
\hline $\begin{array}{l}\text { Quality- } \\
\text { of-life }\end{array}$ & \begin{tabular}{c} 
TRF of thoracic dorsal root ganglion \\
\cline { 2 - 2 }
\end{tabular} & \multirow{2}{*}{$p$-value } \\
\cline { 2 - 3 } Pre-Block & $4.20 \pm 0.66$ & \\
Day 1 & $3.20 \pm 0.85$ & $<0.001$ \\
1 Week & $2.60 \pm 0.86$ & $<0.001$ \\
1 Month & $2.20 \pm 0.96$ & $<0.001$ \\
3 Months & $2.50 \pm 1.25$ & $<0.001$ \\
\hline
\end{tabular}

Table (4): Serial follow-up for quality of sleep Score in patients.

\begin{tabular}{|c|c|c|}
\hline \multirow{2}{*}{$\begin{array}{l}\text { Quality } \\
\text { of sleep }\end{array}$} & TRF of thoracic dorsal root ganglion & \multirow{2}{*}{$p$-value } \\
\hline & Mean \pm SD & \\
\hline Pre-Block & $3.47 \pm 0.94$ & \\
\hline Day 1 & $2.43 \pm 0.97$ & $<0.001$ \\
\hline 1 Week & $1.93 \pm 0.94$ & $<0.001$ \\
\hline 1 Month & $1.50 \pm 0.90$ & $<0.001$ \\
\hline 3 Months & $2.03 \pm 1.22$ & $<0.001$ \\
\hline
\end{tabular}

\section{Discussion}

Dorsal root ganglion (DRG) is a ganglion that is located in dorsal root of spinal cord [10]. It accepts and regulates different type of sensation including pain. Different therapeutic modalities applied to DRG have marked effects on the intractable pain caused by cancer [11].

WHO recommended a stepwise approach in cancer pain management. Step 1, includes the use of paracetamol or a non-steroidal anti-inflammatory drug. Step 2 includes the use of weak opioids. Step 3 includes the use of strong opioids plus adjuvant drugs at any steps [12]. Usually interventional procedures are indicated in cases with refractory pain when analgesic drugs are ineffective or associated with intolerable side effects [13]. They may be considered as step 4 in some algorisms.

We used DRG as a target for intervention due to relatively constant site of the ganglion unlike paravertebral and intercostal nerve which may be displaced by tumor infiltration besides it may induce deafferentation pain and miss a proximal pain generator [14]. Targeting DRG showed a promising result in many published trials [15]. Targeting DRG has many advantages including less risk of inadvertent dural puncture, direct anterior epidural access and more therapeutic value in treating chronic radicular pain [16].

Patients in this study showed great reduction on VAS score on the first day. But higher VAS score was reported on day 1 and week after inter- vention. After one and three months, patients scored similar VAS score with no significant difference.

Thermal radiofrequency ablation (TRF) is an interventional procedure that aims to ablate a nerve to provide pain relief [17]. TRF probe generates an electric current in tissues that are in contact with its probe causing an electromagnetic field which raise tissue temperatures more than $60^{\circ} \mathrm{C}$ for durations more than 60 seconds, which is above the neuro-destructive threshold [18]. Size of the lesion caused by TRF depends on the length of active tip and the gauge of the probe together with the duration of application [19].

TRF on DRG showed efficacy in management of different types of pain e.g., idiopathic trigeminal neuralgia [20], glossopharyngeal therapy for oropharyngeal cancer [21], and facetal medial branch block in back pain [22].

A study recorded 58 patients who underwent PRF to the DRG due to zoster related pain. It concluded that PRF to the DRG is a useful treatment for treatment-resistant cases of herpes zoster related pain. Particularly in herpes zoster patients with intractable pain, application of PRF to the DRG should be considered for control and even pain prevention [23].

In two case reports, TRF was effective in relieving pain for patients suffering from chronic intercostal neuralgia. These results indicate that TRF has significant implications for chronic pain conditions [24]

TRF showed better pain relief when was guided by CT. CT guided TRF was associated with decrease in analgesic consumption and lower VAS score compared to TRF under fluoroscopy [25]

Retrospective data analysis of 49 patients, whom underwent pharmacotherapy, RF of the intercostal nerves (ICN) or RF of the dorsal root ganglia (DRG) in chronic postsurgical thoracic pain. Results showed RF of the DRG was a superior treatment to pharmacotherapy and RF of the ICN in patients [26]

A study investigated effect of TRF combined with Adriamycin injection in DRG for controlling refractory pain induced by rib metastasis of lung cancer. Their result showed significant decrease in morphine doses needed after intervention. Although patients complained of chest wall numbness but it was tolerable [27].

Another study investigated effect of TRF of thoracic paravertebral nerve combined with gluco- 
corticoids for refractory neuropathic pain following breast cancer surgery. Results showed pain relief and quality of life improved. Anesthesia dolorosa and transient burning pain in the corresponding dermatome, which seemed to be related to neuroinjury after radiofrequency treatment, were not seen [28]

Unlike TRF, Pulsed Radio Frequency (PRF) has delayed onset of action usually between 3 to 4 weeks after intervention which is a major limitation for its usage in terminal cancer patients. It is reported that PRF provides short term pain relief [29]. So, we used TRF instead of PRF. However some experts prefer use PRF-DRG instead of TRFDRG for fear of the squeal of TRF-DRG such as neuritis, deafferentation pain, despite PRF short term pain relief $[8]$

A randomized clinical trial compared TRF to PRF in chronic chest pain after mastectomy patients. Eighty patients were included in the analysis. The percentage of patients who had successful response was significantly higher in the thermal $\mathrm{RF}$ group compared to the pulsed RF group at the first week and first, third, and sixth months, with significant difference in post-mastectomy pain intensity, functional improvement, and less rescue analgesia. There was no significant difference in quality of life or patient functional capacity. These results are limited by short duration of follow-up

Despite that PRF showed proper analgesic control. A study compared the clinical efficacy of DRG -PRF to continuous epidural block in patients with persisting pain beyond the acute phase of herpes zoster. Results showed pain decrease was more significant in the PRF group than in the continuous epidural group. The medication doses decreased significantly in the PRF group over time, but not in the continuous epidural group [31]

Regarding complications, the results of this study showed neuritis and moderate to severe back pain.

A 53-year-old women acute onset of lower extremity paresis beginning shortly after right intercostal nerve injections of $2 \mathrm{~mL}$ of preservativefree phenol at the T7, 8, 9 levels. One month after presentation, despite radiographic improvement, the patient showed some clinical improvement, but remained walker dependent and with neurogenic bowel and bladder [32].

Due to effective of the intervention, other complications were not reported in our study including;
Infection (by strict sterilization), Pneumothorax (by respecting the rule of keeping site of skin entrance within the $4 \mathrm{~cm}$ from middle line for all thoracic interventional spinal procedures), deafferentation pain (due to sensory overlap phenomenon of thoracic dermatomes) [33]

This study has several limitations, small sample size and follow-up period was only for three months. We could not asses the relation between origin of chest pain (weather from bone metastasis, pleural origin ...etc.) and efficacy of the intervention.

Evidence showed paravertebral block had advantage over epidural analgesia regarding hemodynamic stability. A randomized trial on 32 patients underwent open lung surgery. Results showed paravertebral block had greater hemodynamic stability than epidural analgesia. Moreover, paravertebral block also required smaller volume of colloids and vasopressors to maintain the target oxygen delivery index. However, both had the same efficacy in providing proper analgesia [34].

A systematic review on 698 participants undergoing thoracotomy. They concluded that paravertebral blockade reduced the risks of developing minor complications compared to thoracic epidural blockade. Paravertebral blockade was as effective as thoracic epidural blockade in controlling acute pain. There was a lack of evidence in other outcomes. There was no difference in 30-day mortality, major complications, or length of hospital stay. There was insufficient data on chronic pain and costs. However, results from this review should be interpreted with caution due to the heterogeneity of the included studies and the lack of reliable evidence [35]

A meta-analysis on 1120 patients concluded that continuous paravertebral block has equivalent analgesic effects to epidural analgesia, wound infiltration and standard care, but is associated with a lower incidence of nausea and vomiting, hypotension and urinary retention than epidural analgesia [36].

It is reported that paravertebral block associated with decreased incidence of chronic pain score, fewer symptoms and signs of chronic pain, and also experience better physical and mental healthrelated quality of life [37].

Ultrasound-guided paravertebral block provides fewer incidences of complications; a study compared ultrasound-guided paravertebral block to thoracic epidural block in patient underwent lung 
surgery. No difference in the frequency of taking supplemental analgesics in both groups. Hypotension occurred significantly more frequently in thoracic epidural block group; on the other hand, the incidences of postoperative nausea and vomiting and pruritus, as well as overall satisfaction score, were similar in both groups [38]

A recent clinical trial compared intercostal nerve block and epidural analgesia-in patients scheduled to undergo thoracoscopic lobectomy and lymphadenectomy. Postoperative pain during postoperative days 0-7 was not significantly different between the groups. Concluding that intercostal nerve block followed by high-dose oral celecoxib seems to be an alternative for epidural Analgesia patients undergoing thoracoscopic lobectomy for lung cancer. Although limited sample size compromised the ability to draw definitive conclusions [39].

\section{Conclusions:}

TRF has better pain relief on long term but with minimal concerns in safety profile.

\section{Financial support and sponsorship:Nil.}

Conflict of Interest: Nil.

\section{References}

1- SHAKOOH S. and BHOSLE P.: Intrathecal nalbuphine: An effective adjuvant for post-operative analgesia. Contract No.: 14.09, 2014.

2- CARACENI A. and PORTENOY R.K.: An international survey of cancer pain characteristics and syndromes. Pain, 82: 263-74, 1999 .

3- COOLEY M.E.: Symptoms in adults with lung cancer: A systematic research review. J. Pain Symptom Manage, 19: 137-53, 2000.

4- LAIRD B.J., SCOTT A.C., COLVIN L.A., MCKEON AL., MURRAY G.D., FEARON K.C., et al.: Pain, depression, and fatigue as a symptom cluster in advanced cancer. J. Pain Symptom Manage, 42: 1-11, 2011.

5- LAIRD B.J., WALLEY J., MURRAY G.D., CLAUSEN E., COLVIN L.A. and FALLON M.T.: Characterization of cancer-induced bone pain: An exploratory study. Supportive Care in Cancer, 19: 1393-401, 2011.

6- GRIPPI M.A., editor Clinical aspects of lung cancer. Seminars in roentgenology, Elsevier, 1990.

7- EWERT T., LIMM H., WESSELS T., RACKWITZ B., VON GARNIER K., FREUMUTH R., et al.: The comparative effectiveness of a multimodal program versus exercise alone for the secondary prevention of chronic low back pain and disability. PM\&R, 1: 798-808, 2009.

8- CHUA N.H., VISSERS K.C. and SLUIJTER M.E.: Pulsed radiofrequency treatment in interventional pain management: Mechanisms and potential indications-a review. Acta. Neurochir., 153: 763-71, 2011.
9- GOVIND J.: Neurolytic blockade for noncancer pain. Bonica's Management of Pain, p. 1467-85, 2010.

10- LI Z., KF S. and XL Z.: Anatomy on Central Nervous, 2009.

11- YG J., LH X. and ZHANG HJIJPR.: The role of dorsal root ganglia in pain mechanism and treatment. Int. J. Pharma Res., 35: 18-22, 2008.

12- Staff WHO, Organization WH.: Cancer pain relief: With a guide to opioid availability: World Health Organization, 1996.

13- HOCHBERG U., ELGUETA M.F. and PEREZ J.: Interventional analgesic management of lung cancer pain. Front Oncol., 7: 17, 2017.

14- GULATI A., SHAH R., PUTTANNIAH V., HUNG J.C. and MALHOTRA V.J.P.M.: A retrospective review and treatment paradigm of interventional therapies for patients suffering from intractable thoracic chest wall pain in the oncologic population. Pain Med., 16: 802-10, 2015.

15- SON K.M., LEE S.M., LEE G.W., AHN M.H. and SON JHJPP.: The impact of lumbosacral transitional vertebrae on therapeutic outcomes of transforaminal epidural injection in patients with lumbar disc herniation. Pain Pract., 16: 688-95, 2016

16- POUNTOS I., PANTELI M., WALTERS G., BUSH D. and GIANNOUDIS PVJDiR.: Safety of epidural corticosteroid injections. Drugs R\&D., 16: 19-34, 2016.

17- WALLACE A.N., GREENWOOD T.J. and JENNINGS JWJJon-o.: Radiofrequency ablation and vertebral augmentation for palliation of painful spinal metastases. Neuro-oncology, 124: 111-8, 2015.

18-NAGDA J.V., DAVIS C.W., BAJWA Z.H. and SIMOPOULOS TTJPp.: Retrospective review of the efficacy and safety of repeated pulsed and continuous radiofrequency lesioning of the dorsal root ganglion/segmental nerve for lumbar radicular pain. Pain Physician, 14: 371-6, 2011.

19- COSMAN Jr E.R., DOLENSKY J.R. and HOFFMAN RAJPM.: Factors that affect radiofrequency heat lesion size. Pain Med., 15: 2020-36, 2014.

20- ERDINE S., OZYALCIN N.S., CIMEN A., CELIK M., TALU G.K. and DISCI RJEjop.: Comparison of pulsed radiofrequency with conventional radiofrequency in the treatment of idiopathic trigeminal neuralgia. Eur. J. Pain, 11: 309-13, 2007

21- KHAN M.Z., IQBAL M.S. and ASHFAQ AJAPIC.: Management of refractory secondary glossobpharyngeal neuralgia with percutaneous radiofrequency thermocoagulation. Anaesth Pain Intensive Care., 14: 38-41, 2010.

22- COSTANDI S., GARCIA-JACQUES M., DEWS T., KOT M., WONG K., AZER G., et al.: Optimal Temperature for Radiofrequency Ablation of Lumbar Medial Branches for Treatment of Facet-Mediated Back Pain. Pain Pract., 16: 961-8, 2016.

23- KIM K., JO D. and KIM E.: Pulsed radiofrequency to the dorsal root ganglion in acute herpes zoster and postherpetic neuralgia. Pain Physician, 20: E411-E8, 2017.

24- ABD-ELSAYED A., LEE S. and JACKSON MJOJ.: Radiofrequency ablation for treating resistant intercostal neuralgia. Ochsner J., 18: 91-3, 2018. 
25- REYAD R.M., GHOBRIAL H.Z., SHAKER E.H., REYAD E.M., SHAABAN M.H., HASHEM R.H., et al.: Modified technique for thermal radiofrequency ablation of Thoracic dorsal root ganglia under combined fluoroscopy and CT guidance: A randomized clinical trial. BMC Anesthesiol., 19: 1-12, 2019.

26- COHEN S.P., SIRECI A., WU C.L., LARKIN T.M., WILLIAMS K.A. and HURLEY RWJPP.: Pulsed radiofrequency of the dorsal root ganglia is superior to pharmacotherapy or pulsed radiofrequency of the intercostal nerves in the treatment of chronic postsurgical thoracic pain. Pain Physician, 9: 227, 2006.

27- XIE G-.L, GUO D-P., LI Z-G, LIU C. and ZHANG W.J.M.: Application of radiofrequency thermocoagulation combined with adriamycin injection in dorsal root ganglia for controlling refractory pain induced by rib metastasis of lung cancer (a STROBE-compliant article). Med., 95, 2016.

28- UCHIDA K.: Radiofrequency treatment of the thoracic paravertebral nerve combined with glucocorticoid for refractory neuropathic pain following breast cancer surgery. Pain Physician, 12: E277-83, 2009.

29- SHANTHANNA H., CHAN P., McCHESNEY J., PAUL J. and THABANE L.J.T.: Assessing the effectiveness of 'pulse radiofrequency treatment of dorsal root ganglion'in patients with chronic lumbar radicular pain: Study protocol for a randomized control trial. Trials, 13: 52, 2012.

30- ABBAS D.N. and REYAD R.M.: Thermal versus super voltage pulsed radiofrequency of stellate ganglion in postmastectomy neuropathic pain syndrome: A prospective randomized trial. Pain Physician, 21: 351-62, 2018.

31- KIM E.D., LEE Y.I. and PARK H.J.: Comparison of efficacy of continuous epidural block and pulsed radiofrequency to the dorsal root ganglion for management of pain persisting beyond the acute phase of herpes zoster. PLoS One, 12: e0183559, 2017.

32- KISSOON N.R., GRAFF-RADFORD J., WATSON J.C. and LAUGHLIN RSJPP.: Spinal cord injury from fluor- oscopically guided intercostal blocks with phenol. Pain Physician, 17: E219-24, 2014.

33- TEIXEIRA A., GRANDINSON M. and SLUIJTER MEJPP.: Pulsed radiofrequency for radicular pain due to a herniated intervertebral disc-an initial report. Pain Pract, 5: $111-5,2005$

34- PINTARIC T.S., POTOCNIK I., HADZIC A., STUPNIK T., PINTARIC M. and NOVAK JANKOVIC V.: Comparison of continuous thoracic epidural with paravertebral block on perioperative analgesia and hemodynamic stability in patients having open lung surgery. Reg. Anesth. Pain Med., 36: 256-60, 2011.

35- YEUNG J.H., GATES S., NAIDU B.V., WILSON M.J. and SMITH FGJCDoSR.: Paravertebral block versus thoracic epidural for patients undergoing thoracotomy. Cochrane Database Syst. Rev., 2016.

36- SCARFE A.J., SCHUHMANN-HINGEL S., DUNCAN J.K., MA N., ATUKORALE Y.N. and CAMERON ALJEjoc-ts.: Continuous paravertebral block for postcardiothoracic surgery analgesia: A systematic review and meta-analysis. Eur. J. Cardio-Thorac. Surg., 50: 10108, 2016.

37- KARMAKAR M.K., SAMY W., LI J.W., LEE A., CHAN W.C., CHEN P.P., et al.: Thoracic paravertebral block and its effects on chronic pain and health-related quality of life after modified radical mastectomy. Reg. Anesth. Pain Med., 39: 289-98, 2014.

38- OKAJIMA H., TANAKA O., USHIO M., HIGUCHI Y., NAGAI Y., IIJIMA K., et al.: Ultrasound-guided continuous thoracic paravertebral block provides comparable analgesia and fewer episodes of hypotension than continuous epidural block after lung surgery. Anaesthesiol. Intensive Ther., 29: 373-8, 2015.

39- UEDA K., HAYASHI M., MURAKAMI J., TANAKA T., UTADA K., HAMANO KJGT, et al.: Intercostal block vs. epidural analgesia in thoracoscopic lung cancer surgery: A randomized trial. Gen Thorac. Cardiovasc. Surg., 68: 254-60, 2020. 


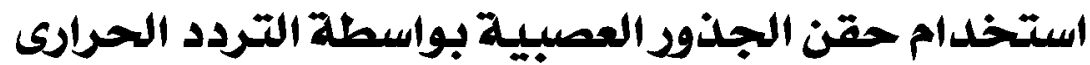

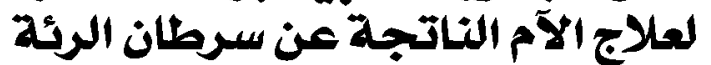

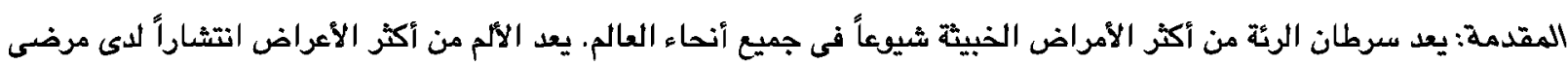

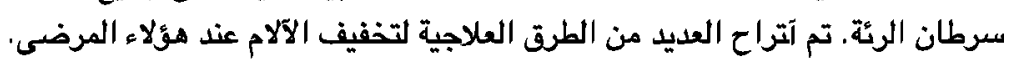
الهدف من الرسالة: هدفت هذه الدراسة إلى تقييم سلامة وفعالية التردد الحرارى للعقدة الجذرية الظهرية فى علاج آلام الصدر السرطانية المزمنة.

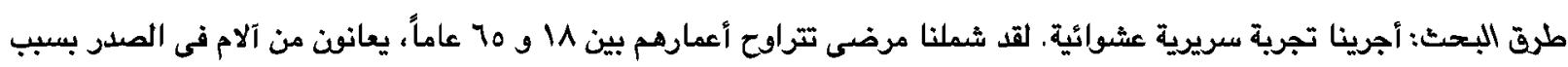

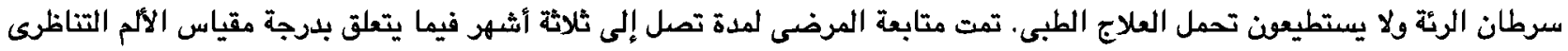
المرئى وجودة المعيشة وجودة النوم ومضاعفات ما بعد الجراحة.

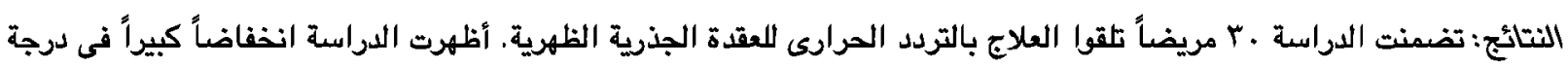

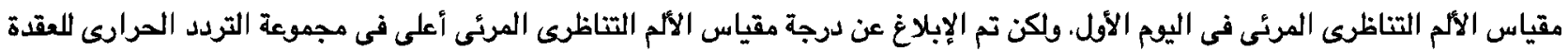

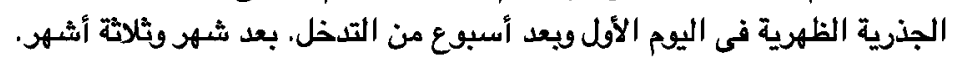
الاستتاج: يتميز يضع الجذو الظهرية بواسطة التردد الحرارى بأمان تام نظراً لقلة مضاعفات ما بعد الأجراء. 